CHRONIC OBSTRUCTIVE PULMONARY DISEASE

\title{
Effect of salbutamol on lung function and chest wall volumes at rest and during exercise in COPD
}

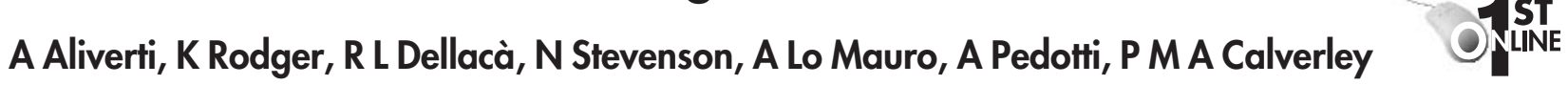

Thorax 2005;60:916-924. doi: 10.1136/thx.2004.037937

Background: Inhaled bronchodilators can increase exercise capacity in chronic obstructive pulmonary disease (COPD) by reducing dynamic hyperinflation, but treatment is not always effective. This may reflect the degree to which the abdomen allows dynamic hyperinflation to occur.

Method: A double blind, randomised, crossover trial of the effect of $5 \mathrm{mg}$ nebulised salbutamol or saline on endurance exercise time was conducted in 18 patients with COPD of mean (SD) age 67.1 (6.3) years and mean (SD) forced expiratory volume in 1 second $\left(\mathrm{FEV}_{1}\right)$ of $40.6(15.0) \%$ predicted. Breathing pattern, metabolic variables, dyspnoea intensity, and total and regional chest wall volumes were measured noninvasively by optoelectronic plethysmography (OEP) at rest and during exercise.

See end of article for authors' affiliations

\section{Correspondence to:}

Dr A Aliverti, Dipartimento di Bioingegneria TBMLab, Politecnico di Milano, 20133 Milano, Italy; andrea.aliverti@ polimi.it

Received 9 December 2004 Accepted 16 June 2005

Published Online First 30 June 2005
Results: Salbutamol increased $\mathrm{FEV}_{1}$, forced vital capacity (FVC) and inspiratory capacity and reduced functional residual capacity (FRC) and residual volume significantly. OEP showed the change in resting FRC to be mainly in the abdominal compartment. Although the mean (SE) end expiratory chest wall volume was 541 (118) $\mathrm{ml}$ lower $(\mathrm{p}<0.001)$ at the end of exercise, the endurance time was unchanged by the bronchodilator. Changes in resting lung volumes were smaller when exercise duration did not improve, but $\mathrm{FEV}_{1}$ still rose significantly after active drug. After the bronchodilator these patients tried to reduce the end expiratory lung volume when exercising, while those exercising longer continued to allow end expiratory abdominal wall volume to rise. The change to a more euvolumic breathing pattern was associated with a lower oxygen pulse and a significant fall in endurance time with higher isotime levels of dyspnoea.

Conclusions: Nebulised salbutamol improved forced expiratory flow in most patients with COPD, but less hyperinflated patients tried to reduce the abdominal compartmental volume after active treatment and this reduced their exercise capacity. Identifying these patients has important therapeutic implications, as does an understanding of the mechanisms that control chest wall muscle recruitment.
C hronic obstructive pulmonary disease (COPD) is characterised by the presence of persistent and usually progressive airflow obstruction. ${ }^{1}$ When expiratory airflow limitation develops during tidal breathing, patients must allow the end expiratory lung volume (EELV) to rise to permit a higher expiratory flow rate (dynamic hyperinflation) or stop exercising relatively quickly (euvolumic response). ${ }^{2}$ Either way, the patient's exercise tolerance is limited and this is associated with a worse state of health. ${ }^{3}$

Bronchodilator drugs such as salbutamol, a short acting $\beta$ agonist, are widely prescribed for the symptomatic relief of breathlessness in COPD. ${ }^{4}$ Unfortunately, not all patients benefit from bronchodilator therapy and the relationship between the change in spirometric parameters and the subsequent exercise capacity is weak. ${ }^{5}$ A reduction in EELV during exercise has been reported with short acting inhaled drugs $^{6}$ and long acting anticholinergic agents and $\beta$ agonists, ${ }^{78}$ and this relates to the reported reduction in dyspnoea. However, exercise duration does not always increase even when lung mechanics improve.' We have previously described two different patterns of changes in chest wall volume during exercise in COPD-euvolumic patients who try to reduce end expiratory chest wall volume during exercise and hyperinflators who let the chest wall volume rise, mainly by a change in abdominal compartmental volume. ${ }^{2}$ Bronchodilators can reduce total chest wall volume at rest, ${ }^{10}$ but nothing is known about how these drugs affect the breathing strategy adopted during exercise and whether this relates to the subsequent exercise performance.

We hypothesised that bronchodilator treatment would reduce chest wall volumes at rest and during exercise.
Moreover, we anticipated that patients who increased their end expiratory abdominal compartmental volume during exercise after the active drug would be able to exercise for longer. To test these ideas we conducted a double blind, randomised, crossover trial of the effect of nebulised salbutamol on lung function, chest wall volume, and endurance exercise capacity in patients with stable COPD.

\section{METHODS}

\section{Subjects}

Eighteen patients with clinically stable COPD diagnosed by accepted criteria were recruited to the study. ${ }^{11}$ All had been smokers and complained of exertional dyspnoea. None had clinical or physiological features of bronchial asthma or a history of exacerbation in the previous 6 weeks. There were no co-morbid conditions limiting exercise. Patients were studied before pulmonary rehabilitation and were unfamiliar with physiological exercise testing; they discontinued their routine bronchodilator drugs for 4 hours (short acting) or 12 hours (long acting) before attendance. The protocol was approved by the district research ethics committee and informed consent was obtained by all patients.

Abbreviations: COPD, chronic obstructive pulmonary disease; EELV, end expiratory lung volume; $\mathrm{F}_{R}$, breathing frequency; $\mathrm{FEV}_{1}$, forced expiratory volume in 1 second; FRC, functional residual capacity; FVC, forced vital capacity; IC, inspiratory capacity; OEP, optoelectronic plethysmography; RER, respiratory exchange ratio; RV, residual volume; $\mathrm{TE}$, expiratory time; TI, inspiratory time; TGV, thoracic gas volume; TLC, total lung capacity; $V_{A B}$, volume of abdomen; $V C W$, volume of total chest wall; $V_{E}$, minute ventilation; $V_{R C}$, rib cage volume; $\mathrm{VT}$, tidal volume; Wmax, maximum workload 


\section{Study design}

The study was of a randomised, double blind, crossover design. During an initial screening visit patients were thoroughly familiarised with all procedures and symptom rating scales, and pulmonary function tests and symptom limited incremental cycle exercise testing were performed to determine maximum workload (Wmax). The subjects were then randomised to receive either high dose nebulised salbutamol or placebo. Each subject attended twice within a period of 3-10 days. At each visit pulmonary function, subdivisions of lung and chest wall volumes, and resting breathing pattern were measured. Salbutamol or placebo treatment was then administered by inhalation over approximately 15 minutes. Thirty minutes after the treatment finished, pulmonary function, subdivisions of lung and chest wall volumes, and resting breathing pattern measurements were repeated. Finally, a symptom limited submaximal (70\% Wmax) constant load cycle exercise test was performed.

\section{Procedures and measurements Resting lung function testing}

Spirometry and body plethysmography were performed using automated testing equipment (Medgraphic Autolink 1085D, Medical Graphics, St Paul, MN, USA) according to recommended standards. ${ }^{12}$ Specialised flow/volume loop software was used to measure the $\mathrm{FEV}_{1}, \mathrm{FVC}$, and maximal expiratory flow indices $\left(\mathrm{FEF}_{25 \%}\right.$ and $\left.\mathrm{FEF}_{75 \%}\right)$ during spirometric testing. Thoracic gas volume (TGV) was measured with patients seated in the body plethysmograph and panting against a closed shutter at a frequency of $\sim 1 \mathrm{~Hz}$ with their cheeks supported. Total lung capacity (TLC) was obtained as the sum of TGV and the inspiratory capacity measured soon after reopening the shutter; residual capacity (RV) was calculated as the difference between TLC and a slow expiratory vital capacity; functional residual capacity (FRC) was obtained from TGV corrected for any difference between the volume at which the shutter was closed and the average end expiratory volume of the four preceding tidal breaths.

\section{Chest wall volumes}

Procedures for measuring chest wall volumes by optoelectronic plethysmography (OEP) have been described in detail in our previous publications. ${ }^{2}{ }^{13}$ The position of 89 retroreflective markers placed front and back over the chest wall from clavicles to pubis was recorded at $60 \mathrm{~Hz}$ by six calibrated video cameras (OEP System BTS, Milan, Italy) placed three in front of the subject and three behind. From the three dimensional coordinates of the markers obtained by stereophotogrammetry, a specialised software based on Gauss's theorem provided the continuous measurement of the volume of the total chest wall (VCW), rib cage (VRC), and abdomen $(\mathrm{VAB})$, with $\mathrm{VCW}=\mathrm{VRC}+\mathrm{VAB}$.

The markers were placed on the patients after the first spirometric and body box evaluation. They were then asked to sit on an unsupported chair and OEP measurements were taken during 3 minutes of spontaneous breathing at rest and during a series of 3-4 slow vital capacity (SVC) manoeuvres. From the breath-by-breath measurements of $\mathrm{V}_{\mathrm{CW}}$ during quiet breathing, the ventilatory pattern including tidal volume $(V T)$, breathing frequency $(f R)$, minute ventilation $(\mathrm{VE})$, inspiratory (TI) and expiratory $(\mathrm{TE})$ time, mean inspiratory (VT/TI) and expiratory (VT/Te) flow was determined by calculating the average values of these variables. From the OEP measurements carried out during the SVC manoeuvre, the mean operating total and compartmental chest wall volumes (VCW, VRC and VAB at TLC, FRC and RV) were obtained.

\section{Treatment}

Treatments were administered using a face mask from an Acorn nebuliser at a flow rate of $4 \mathrm{l} / \mathrm{min}$ over a period of 15 minutes. The total volume of nebulised solution was $2.5 \mathrm{ml}$ for all patients: salbutamol $(5 \mathrm{mg}$ ) was compared with a placebo which consisted of sterile $0.9 \%$ sodium chloride solution.

\section{Exercise testing}

The two exercise tests were performed on an electrically braked cycle ergometer at $70 \%$ of the maximum work rate achieved during the incremental exercise test. During exercise, standard measurements $\left(\mathrm{VO}_{2}, \mathrm{VCO}_{2}\right.$, heart rate, oxygen saturation) were collected using a cardiopulmonary exercise testing system (Medical Graphics, St Paul, MN, USA) with patients wearing a noseclip and breathing though a mass flow sensor $(70 \mathrm{ml}$ dead space). The tests consisted of a steady state resting period of 90 seconds, a subsequent 90 seconds warming up by unloaded pedalling, followed by an immediate increase in work rate; pedalling frequencies were maintained at approximately 60 revolutions per minute. Initial and end exercise values (" $1 \mathrm{~min}^{\prime}$ and "stop" in the following text and figures) were defined respectively as the mean over the period between 45 and 75 seconds from the beginning of loaded exercise and over the last 30 seconds of loaded exercise.

OEP measurements were also performed during constant workload exercise with the patients wearing the previously positioned markers. To prevent the arms from obscuring relevant markers, the patient grasped handles positioned laterally at the mid sternum level. Special care was taken to allow the visibility of the markers placed on the thoracoabdominal surface and to analyse the patients with the same posture (trunk position) during the two different tests. From OEP measurements the ventilatory pattern was determined, including breath-by-breath variations of end expiratory and end inspiratory volumes of VCW, VRC and VAB.

At rest, every 1 minute during exercise, and at the end of exercise, subjects rated the intensity of their breathing and leg discomfort using the modified Borg scale. ${ }^{14}$

Table 1 Baseline anthropometric, spirometric, lung function, exercise and resting breathing pattern data in study patients $(n=18)$

\begin{tabular}{|c|c|c|}
\hline & Mean (SD) & $\%$ predicted (SD) \\
\hline$M / F$ & $15 / 3$ & \\
\hline Age (years) & $67.1(6.3)$ & \\
\hline Body mass index $\left(\mathrm{kg} / \mathrm{m}^{2}\right)$ & $24.3(4.2)$ & \\
\hline \multicolumn{3}{|l|}{ Lung function } \\
\hline $\mathrm{FEV}_{1}$ (I) & $1.14(0.41)$ & $40.6(15.0)$ \\
\hline FVC (I) & $2.74(0.72)$ & 74.5 (17.2) \\
\hline $\mathrm{FEV}_{1} / \mathrm{FVC}(\%)$ & $42.4(11.6)$ & \\
\hline $\mathrm{FEF}_{25 \%}(\mathrm{l} / \mathrm{s})$ & $1.20(0.90)$ & $19.2(13.6)$ \\
\hline $\mathrm{FEF}_{75 \%}(\mathrm{l} / \mathrm{s})$ & $0.20(0.07)$ & $17.8(5.9)$ \\
\hline TLC (l) & $7.87(1.04)$ & $125.7(11.6)$ \\
\hline FRC (l) & $5.86(1.10)$ & $175.8(26.0)$ \\
\hline RV (I) & $4.80(1.03)$ & $215.6(47.1)$ \\
\hline IC (I) & $2.02(0.47)$ & $68.2(16.7)$ \\
\hline \multicolumn{3}{|l|}{ Resting breathing pattern } \\
\hline VT (l) & $0.805(0.221)$ & \\
\hline $\mathrm{fR}_{\mathrm{R}}$ (breaths/min) & $23.9(9.5)$ & \\
\hline $\mathrm{TI}(\mathrm{s})$ & $1.17(0.29)$ & \\
\hline TE $(s)$ & $1.99(0.73)$ & \\
\hline VT/Tı (I/s) & $0.712(0.081)$ & \\
\hline $\mathrm{VT} / \mathrm{TE}(\mathrm{I} / \mathrm{s})$ & $0.432(0.102)$ & \\
\hline VE $(I / \mathrm{min})$ & $15.9(0.8)$ & \\
\hline \multicolumn{3}{|l|}{ Exercise performance } \\
\hline Wmax (watt) & $66.8(16.2)$ & \\
\hline Exercise time at $70 \% \mathrm{~W} \max (\mathrm{s})$ & $318(224)$ & \\
\hline
\end{tabular}



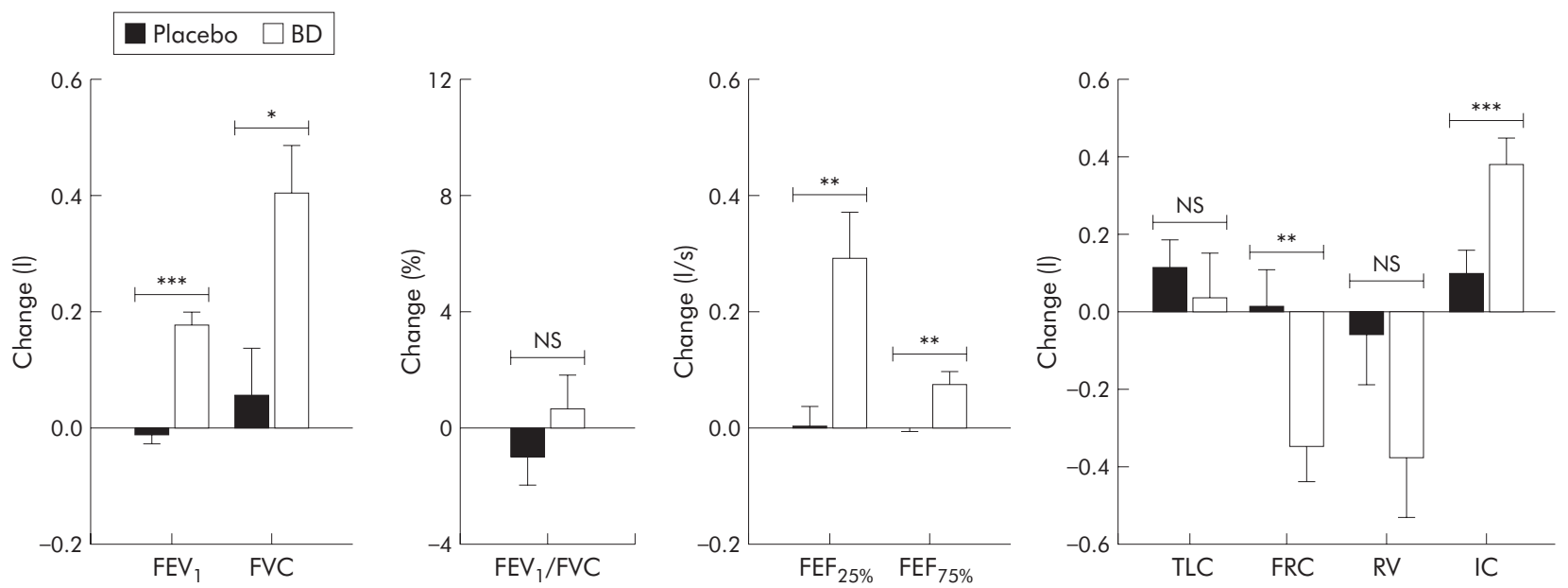

Figure 1 Effect of nebulised treatment on pulmonary function and lung volumes. ${ }^{* * *} \mathrm{p}<0.001 ;{ }^{* *} \mathrm{p}<0.01 ;{ }^{*} \mathrm{p}<0.05$; NS, not significant. BD, bronchodilator; $\mathrm{FEV}_{1}$, forced expiratory volume in 1 second; FVC, forced vital capacity; FEF, forced expiratory flow; TLC, total lung capacity; FRC, functional residual capacity; RV, residual volume; IC, inspiratory capacity. Data are expressed as mean (SE).

\section{Statistical analysis}

Data are presented as mean (SE) unless otherwise stated. Paired or unpaired Student $t$ tests were used as appropriate to compare placebo with salbutamol and improvers with nonimprovers. A statistical significance of 0.05 was used for all analyses, with appropriate Bonferroni corrections for multiple comparisons. Randomisation was performed using a table of random numbers to generate a concealed subject allocation card. As we did not have data about the effect of bronchodilators on abdominal compartmental volume change before this study, the trial was powered on an expected difference in inspiratory capacity of $200 \mathrm{ml}$ between treatment groups and our 18 subjects had a $90 \%$ power to detect this difference at the $5 \%$ level of significance. To
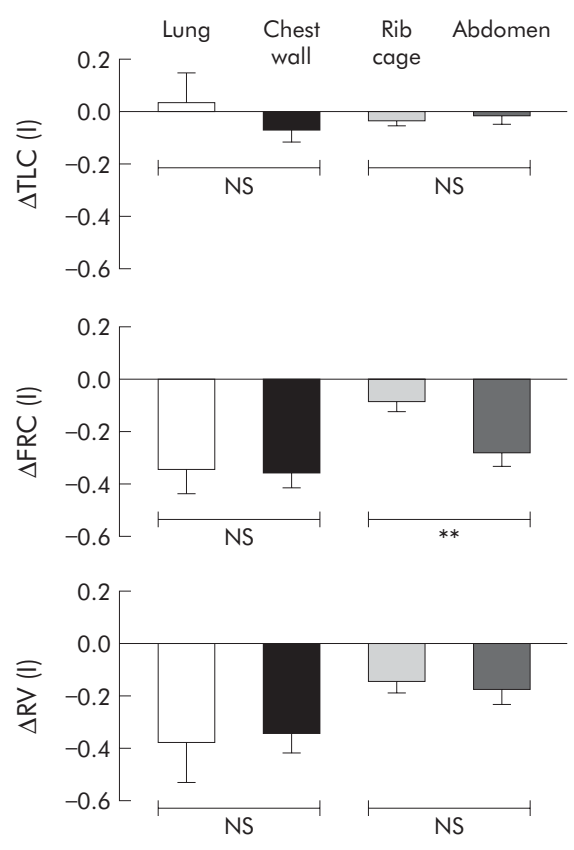

Figure 2 Effect of nebulised treatment on lung and chest wall volume changes at total lung capacity (TLC), functional residual capacity (FRC), and residual volume (RV). ${ }^{* *} \mathrm{p}<0.01$; NS, not significant. Data are expressed as mean (SE). identify the mechanisms determining the response to treatment, we decided a priori to classify patients whose post salbutamol exercise duration was greater as "improvers" and those whose exercise duration was equal to or less than that after saline as "non-improvers", irrespective of the magnitude of the difference after the drug. Statistical analysis of these secondary end points is included to aid future hypothesis generation and should be treated with caution, given the number of patients involved.

\section{RESULTS}

Demographic data for the study patients are shown in table 1 . They were an elderly group with moderate to severe airflow limitation, significantly raised lung volumes, and markedly impaired exercise capacity.

\section{Treatment effects: resting data}

The effect of treatment on baseline pulmonary function is shown in fig 1 . Comparing the changes in spirometric parameters and lung volumes after placebo and salbutamol in the whole population of patients, statistically significant differences were found in $\mathrm{FEV}_{1}(\mathrm{p}<0.001)$, FVC $(\mathrm{p}<0.05)$, $\mathrm{FEF}_{25 \%}(\mathrm{p}<0.01), \operatorname{FEF}_{75 \%}(\mathrm{p}<0.01), \operatorname{FRC}(\mathrm{p}<0.01)$, and IC $(\mathrm{p}<0.001)$.

The changes in the subdivisions of lung volume, measured by total body plethysmography, were not statistically different from the changes in the chest wall at the corresponding volumes (TLC, FRC and RV) measured by OEP (fig 2). The decrease in FRC induced by salbutamol was accomplished by a decrease in VAB rather than VRC, while the decrease in RV was the result of a decrease in both VRC and $\mathrm{VAB}$ (fig 2). Although the thoracoabdominal configuration at FRC could be considered relaxed, at RV it was active. Hence, the greater reduction in VAB than in VRC at FRC shown in fig 2 is likely to represent a greater compliance of the abdominal compartment than of the rib cage compartment. In this situation, the change in the thoracoabdominal configuration at active RV reflects the actions of the expiratory muscles on the two compartments and not only their inherent mechanical properties.

The ventilatory pattern analysed at rest after placebo and bronchodilator drug is shown in table 2. There were no changes in the timing or frequency of respiration after any treatment, but mean expiratory flow $(\mathrm{VT} / \mathrm{TE})$ and $\mathrm{VE}$ showed significant increases after salbutamol $(p<0.05)$. 
Table 2 Resting and end exercise ventilatory pattern, metabolic and cardiac variables after placebo and salbutamol

\begin{tabular}{|c|c|c|c|c|}
\hline & \multicolumn{2}{|c|}{ After placebo (mean (SE) exercise time 316 (52) s) } & \multicolumn{2}{|c|}{ After salbutamol (mean (SE) exercise time $330(35) \mathrm{s}$} \\
\hline & Rest & End exercise & Rest & End exercise \\
\hline $\mathrm{V}_{\mathrm{T}}(\mathrm{l})$ & $0.805(0.052)$ & $1.325(0.074)$ & $0.875(0.065)$ & $1.371(0.064)$ \\
\hline$f_{R}$ (breaths/min) & $23.9(2.2)$ & $34.3(1.8)$ & $25.2(2.2)$ & $32.7(2.1)$ \\
\hline TI $(s)$ & $1.17(0.07)$ & $0.82(0.05)$ & $1.18(0.08)$ & $0.90(0.07)$ \\
\hline $\mathrm{TE}(\mathrm{s})$ & $1.99(0.17)$ & $1.08(0.06)$ & $1.94(0.21)$ & $1.26(0.13)^{*}$ \\
\hline$V_{T} / T_{I}(l / s)$ & $0.71(0.04)$ & $1.71(0.10)$ & $0.75(0.04)$ & $1.65(0.10)$ \\
\hline $\mathrm{VT}_{\mathrm{T}} / \mathrm{TE}(\mathrm{I} / \mathrm{s})$ & $0.43(0.02)$ & $1.30(0.07)$ & $0.48(0.03)^{*}$ & $1.25(0.09)$ \\
\hline VE $(\mathrm{l} / \mathrm{min})$ & $15.9(0.8)$ & $43.7(2.5)$ & $17.35(0.99)^{*}$ & $41.6(2.8)$ \\
\hline $\mathrm{VO}_{2}(\mathrm{l} / \mathrm{min})$ & $0.34(0.02)$ & $0.93(0.05)$ & $0.33(0.02)$ & $0.95(0.05)$ \\
\hline $\mathrm{VCO}_{2}(1 / \mathrm{min})$ & $0.29(0.02)$ & $0.87(0.05)$ & $0.28(0.01)$ & $0.91(0.06)$ \\
\hline RER & $0.84(0.02)$ & $0.93(0.02)$ & $0.86(0.03)$ & $0.96(0.03)^{*}$ \\
\hline HR (beats/min) & $91.1(3.6)$ & $114.4(4.4)$ & $89.1(2.0)$ & $116.2(4.1)$ \\
\hline $\mathrm{VO}_{2} / \mathrm{HR}$ (ml/beat) & $3.6(0.2)$ & $8.7(0.4)$ & $3.7(0.2)$ & $8.3(0.6)$ \\
\hline $\mathrm{SaO}_{2}(\%)$ & $96.0(0.6)$ & $93.6(0.5)$ & $96.2(0.5)$ & $94.5(0.6)$ \\
\hline Breathlessness & $0.75(0.25)$ & $5.61(0.48)$ & $1.00(0.30)$ & $6.28(0.52)$ \\
\hline Leg effort & $0.72(0.24)$ & $5.33(0.56)$ & $0.83(0.23)$ & $6.03(0.68)$ \\
\hline
\end{tabular}

\section{Treatment effects: exercise data}

At the end of the symptom limited constant workload exercise after placebo treatment, end expiratory Vcw increased by 386 (106) $\mathrm{ml}$ (fig 3, left panel) and end expiratory VRC increased by 426 (91) $\mathrm{ml}$ (fig 3, middle panel). In contrast, end expiratory VAB remained practically constant throughout exercise with the end inspiratory volumes rising to accommodate the increases in VRC (fig 3, right panel). End inspiratory VCw approached the TLC values measured before exercise and this was accomplished by increases in both VRC and VAB.

The dynamic behaviour of Vcw after salbutamol in the overall population of patients was very similar to that observed after placebo, the only difference being that the operating volumes were shifted toward lower values. End expiratory Vcw fell in four patients after placebo treatment (mean change $64 \mathrm{ml}$ ) and in five after salbutamol (mean change $172 \mathrm{ml}$ ). As a result, after bronchodilator treatment end inspiratory VCw did not reach the TLC values and at end of exercise a significant inspiratory reserve volume was still present.

The ventilatory pattern at end of exercise did not differ between placebo and bronchodilator treatment groups apart from a significant prolongation in expiratory time at end of exercise after salbutamol, in keeping with the lower end expiratory Vcw (table 2). There were no differences in the degree of oxygen desaturation during exercise between placebo and salbutamol days.

In the overall population of patients, symptom limited exercise endurance time did not improve significantly after salbutamol compared with placebo (330 (35) s v 316 (53) s).

\section{Treatment effects: responder analysis}

In 12 patients endurance time increased by 106 (23) s (a mean improvement of $86(30) \%)$, while in the other six patients it decreased by $170(42)$ s (-34 (10)\%). Individual changes are shown in fig 4 .

Table 3 shows baseline data and the response to bronchodilator treatment. Non-improvers tended to have smaller Wmax (but longer endurance times) and better pulmonary function $\left(\mathrm{FEV}_{1}, \mathrm{FVC}\right.$, expiratory flows) than improvers, although only baseline FRC and RV achieved statistical significance $(\mathrm{p}<0.05)$, the improvers exhibiting more hyperinflation and gas trapping before the bronchodilator. After salbutamol treatment improvers had significantly increased $\mathrm{FEV}_{1}(\mathrm{p}<0.001)$, FVC $(\mathrm{p}<0.001)$, forced expiratory flows $(\mathrm{p}<0.01)$, IC $(\mathrm{p}<0.001)$ and decreased FRC $(\mathrm{p}<0.01)$ and $\mathrm{RV}(\mathrm{p}<0.01)$. In contrast, in non-improvers $\mathrm{FEV}_{1}$ was
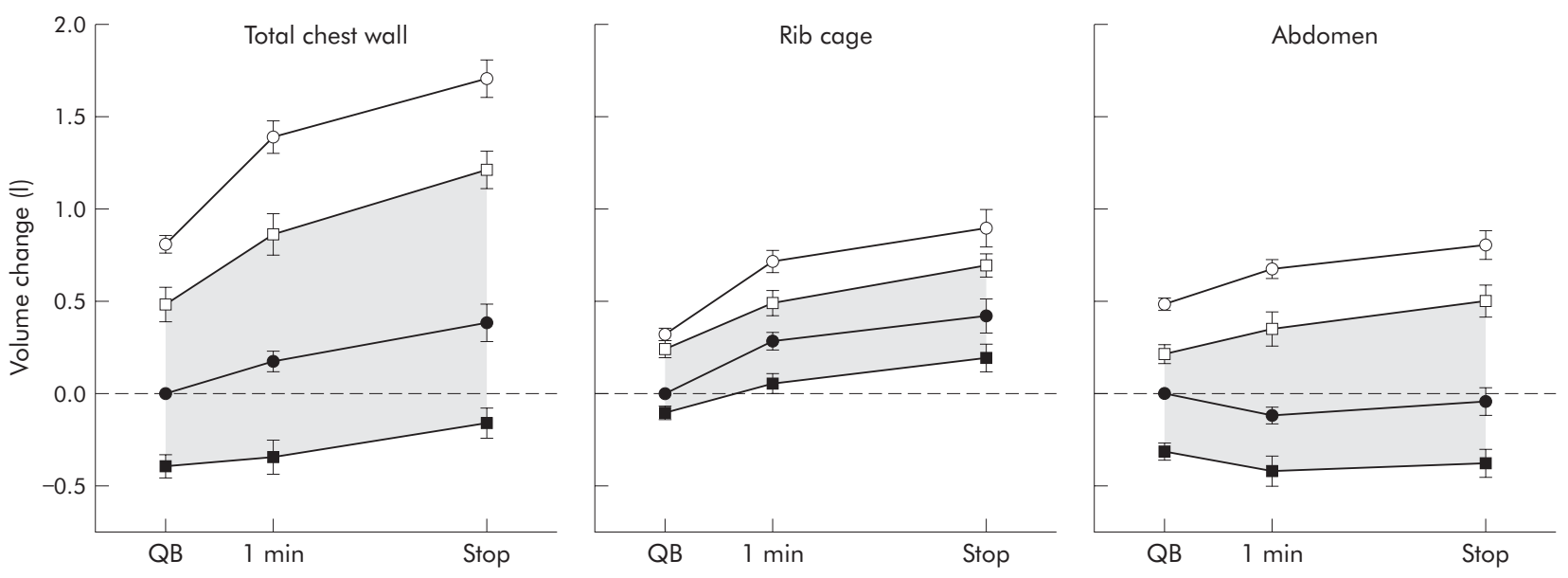

Figure 3 Changes in end expiratory volume (closed symbols) and end inspiratory volume (open symbols) after placebo (circles) and bronchodilator (squares) during quiet breathing (QB), after 1 minute of exercise, and in the 30 seconds before stopping exercise (Stop). All values are referred to end expiratory volumes during $\mathrm{QB}$ after placebo treatment. The shaded area indicates the range of volume changes during the test after bronchodilator. Data are expressed as mean (SE); $n=18$. 

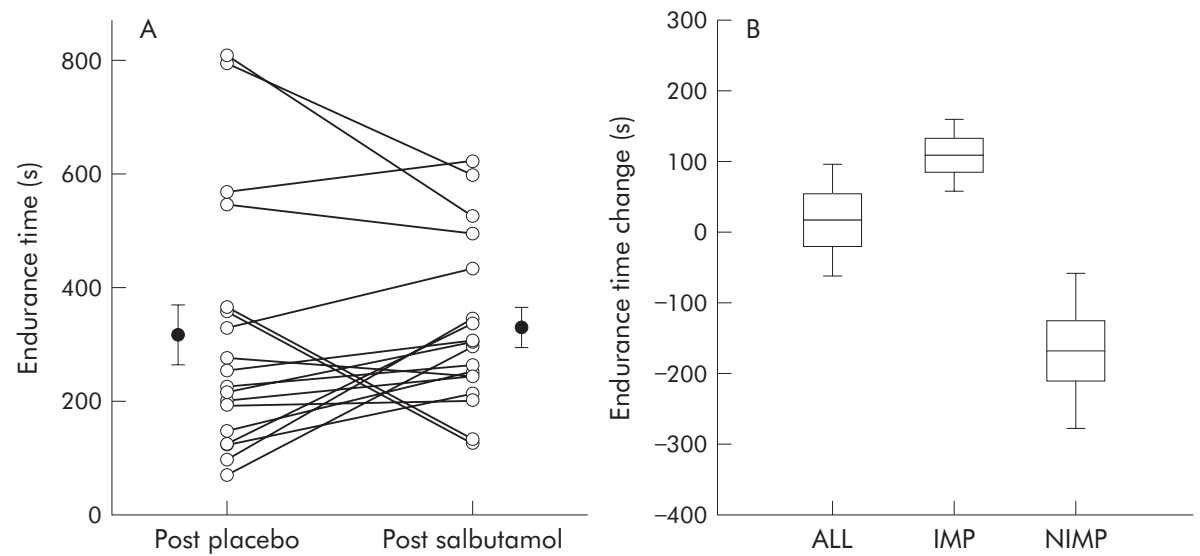

Figure 4 (A) Group mean and individual data for constant workload exercise endurance time after placebo and salbutamol. The lines connect data from the same patient. Error bars represent standard error of the mean. (B) Mean, SE, 5\% and $95 \%$ confidence intervals of the difference in endurance time in all subjects (ALL) and in those in whom endurance time increased (IMP) or did not improve (NIMP) after salbutamol.

increased $(\mathrm{p}<0.01)$ after salbutamol; the other variables showed a trend toward improvement but not significantly. An improvement in resting IC of more than $200 \mathrm{ml}$ (the day to day reproducibility) was present in $50 \%$ of these patients.

At rest the ventilatory pattern, metabolic rate, and dyspnoea intensity were similar in the two groups after both placebo and salbutamol treatment (tables 3 and 4).

After the saline placebo, patients not improving stopped exercise at a lower minute ventilation and a lower dyspnoea intensity than those who benefited from treatment. The peak minute ventilation was unaffected by the test drug but the oxygen pulse fell significantly $(\mathrm{p}<0.01)$ at end of exercise following salbutamol in the non-improvers (table 4). End inspiratory and end expiratory volumes of the entire chest wall (fig 5A) and of the rib cage and abdominal compartment (data not shown) during rest and exercise after placebo treatment were very similar in the two groups. In contrast, two different patterns of change in VCw occurred during exercise after bronchodilator treatment. While the improvers continued to increase both end inspiratory and end expiratory $\mathrm{Vcw}$, the non-improvers maintained a significantly lower total VCw $(p<0.05$, fig $5 B)$. This was entirely due to a difference in the abdominal compartmental volume (fig 6). Ensemble averages of flow-volume curves during forced expiratory manoeuvres and tidal breathing at rest and end of exercise are shown in fig 7A and B for improvers and nonimprovers. Volume data reported in the graphs have been obtained by integrating the flow measured at the mouth and

Table 3 Anthropometric, spirometric, lung function, exercise and resting breathing pattern data before and after bronchodilator (BD) treatment with salbutamol in patients who increased exercise time after treatment (improvers) and those who did not (non-improvers)

\begin{tabular}{|c|c|c|c|c|c|c|}
\hline & \multicolumn{3}{|l|}{$\begin{array}{l}\text { Improvers } \\
(n=12)\end{array}$} & \multicolumn{3}{|l|}{$\begin{array}{l}\text { Non-improvers } \\
(n=6)\end{array}$} \\
\hline$M / F$ & $11 / 1$ & & & $4 / 2$ & & \\
\hline Age (years) & $67.6(1.9)$ & & & $66.0(2.7)$ & & \\
\hline BMI $\left(\mathrm{kg} / \mathrm{m}^{2}\right)$ & $23.9(1.2)$ & & & $25.2(2.0)$ & & \\
\hline \multirow[t]{2}{*}{ Wmax (watt) } & $65.9(4.8)$ & & & $49.0(6.6)$ & & \\
\hline & Before BD & After BD & Difference $(95 \% \mathrm{Cl})$ & Before BD & After BD & Difference $(95 \% \mathrm{Cl})$ \\
\hline Exercise time (s) & $212(38)$ & $319(33)$ & $107(56$ to 157$)$ & $524(95)+\dagger$ & $354(85)$ & $-171(-280$ to -62$)$ \\
\hline $\mathrm{FEV}_{1}$ (I) & $1.06(0.12)$ & $1.27(0.13)^{\star * \star}$ & $0.21(0.14$ to 0.27$)$ & $1.30(0.15)$ & $1.42(0.14)^{* *}$ & $0.12(0.04$ to 0.19$)$ \\
\hline $\mathrm{FEV}_{1}$ (\% pred) & $37.3(4.4)$ & $44.7(4.9)^{* * *}$ & $7.4(4.8$ to 10.0$)$ & $47.2(5.2)$ & $51.5(5.1)^{\star *}$ & $4.3(1.5$ to 7.2$)$ \\
\hline FVC (I) & $2.66(0.16)$ & $3.15(0.17)^{\star \star \star}$ & $0.49(0.27$ to 0.71$)$ & $2.88(0.41)$ & $3.12(0.37)$ & $0.24(-0.106$ to 0.58$)$ \\
\hline FVC (\% pred) & $72.1(3.9)$ & $85.7(5.3)^{\star \star \star}$ & 13.7 (7.0 to 20.3$)$ & $79.3(9.7)$ & $86.2(8.3)$ & $6.8(-2.4$ to 16.0$)$ \\
\hline $\mathrm{FEV}_{1} / \mathrm{FVC}(\%)$ & $39.4(2.9)$ & $40.3(3.2)$ & $0.9(-2.0$ to 3.8$)$ & $47.8(5.4)$ & $48.0(5.0)$ & $0.2(-6.6$ to 6.9$)$ \\
\hline $\mathrm{FEF}_{25 \%}(\mathrm{l} / \mathrm{s})$ & $1.08(0.29)$ & $1.44(0.39)^{* *}$ & $0.36(0.13$ to 0.60$)$ & $1.42(0.26)$ & $1.57(0.22)$ & $0.15(-0.11$ to 0.42$)$ \\
\hline $\mathrm{FEF}_{75 \%}(\mathrm{l} / \mathrm{s})$ & $0.18(0.02)$ & $0.27(0.35)^{\star *}$ & $0.09(0.03$ to 0.15$)$ & $0.22(0.03)$ & $0.27(0.06)$ & $0.05(-0.05$ to 0.15$)$ \\
\hline TLC (I) & $8.17(0.26)$ & $8.05(0.35)$ & $-0.13(-0.61$ to 0.36$)$ & $7.27(0.45)$ & $6.24(1.24)$ & $-1.03(-4.09$ to 2.03$)$ \\
\hline TLC (\% pred) & $128.0(3.3)$ & $125.8(4.5)$ & $-2.2(-9.6$ to 5.3$)$ & $120.0(5.6)$ & $119.8(5.1)$ & $2.2(-7.5$ to 11.9$)$ \\
\hline FRC (I) & $6.27(0.28)$ & $5.98(0.34)^{* *}$ & $-0.36(-0.57$ to -0.15$)$ & $5.04(0.38) \dagger$ & $4.91(0.29)$ & $-0.12(-0.79$ to 0.54$)$ \\
\hline FRC ( $\%$ pred) & $185.6(6.6)$ & $177.3(8.0)^{* *}$ & $-11.3(-18.4$ to -4.2$)$ & $155.2(10.4) \dagger$ & $145.6(9.4) \dagger$ & $-2.3(-25.3$ to 20.6$)$ \\
\hline RV (I) & $5.20(0.26)$ & $4.74(0.26)^{\star *}$ & $-0.52(-0.85$ to -0.20$)$ & $4.01(0.34) \dagger$ & $4.13(0.22)$ & $0.12(-0.75$ to 1.00$)$ \\
\hline RV (\% pred) & $231.7(12.7)$ & $211.7(11.8)$ & $-24.1(-39.4$ to -8.8$)$ & $182.2(18.7) \dagger$ & $179.4(7.5)$ & $6.5(-34.7$ to 47.7$)$ \\
\hline IC (I) & $1.91(0.13)$ & $2.23(0.12)^{\star \star \star}$ & $0.42(0.23$ to 0.60$)$ & $2.23(0.19)$ & $2.45(0.30)$ & $0.22(-0.12$ to 0.57$)$ \\
\hline IC (\% pred) & $63.7(4.7)$ & $77.1(4.7)^{* * *}$ & 13.4 (8.2 to 18.7$)$ & $76.2(7.2)$ & $89.6(7.3)$ & $9.7(-6.1$ to 25.4$)$ \\
\hline VT (I) & $0.81(0.04)$ & $0.91(0.07)$ & $0.10(-0.01$ to 0.21$)$ & $0.80(0.14)$ & $0.80(0.14)$ & $0.01(-0.09$ to 0.10$)$ \\
\hline $\mathrm{fR}_{\mathrm{R}}$ (breaths/min) & $21.8(2.4)$ & $23.7(2.7)$ & $1.9(-2.4$ to 6.1$)$ & $28.0(4.5)$ & $28.4(3.8)$ & $0.5(-3.5$ to 4.5$)$ \\
\hline $\mathrm{TI}(\mathrm{s})$ & $1.21(0.09)$ & $1.22(0.12)$ & $0.01(-0.16$ to 0.19$)$ & $1.09(0.10)$ & $1.10(0.07)$ & $0.01(-0.10$ to 0.11$)$ \\
\hline TE (s) & $2.04(0.21)$ & $2.01(0.28)$ & $-0.03(-0.42$ to 0.36$)$ & $1.88(0.32)$ & $1.78(0.26)$ & $-0.10(-0.67$ to 0.47$)$ \\
\hline $\mathrm{V}_{\mathrm{T}} / \mathrm{T}_{\mathrm{I}}(\mathrm{I} / \mathrm{s})$ & $0.69(0.04)$ & $0.77(0.04)$ & $0.07(0.01$ to 0.13$)$ & $0.74(0.10)$ & $0.74(0.11)$ & $-0.00(-0.13$ to 0.12$)$ \\
\hline $\mathrm{VT} / \mathrm{TE}(\mathrm{l} / \mathrm{s})$ & $0.43(0.03)$ & $0.49(0.04)$ & 0.07 (0.02 to 0.11$)$ & $0.44(0.05)$ & $0.46(0.05)$ & $0.02(-0.08$ to 0.11$)$ \\
\hline
\end{tabular}


Table 4 Ventilatory pattern and metabolic data in resting conditions and at end of exercise after placebo and after bronchodilator (BD) treatment with salbutamol in improvers and non-improvers

\begin{tabular}{|c|c|c|c|c|}
\hline & \multicolumn{2}{|l|}{ Improvers } & \multicolumn{2}{|c|}{ Non-improvers } \\
\hline & Placebo & BD & Placebo & BD \\
\hline \multicolumn{5}{|l|}{ At rest } \\
\hline VE (I/min) & $15.6(0.8)$ & $16.4(1.9)$ & $17.7(1.1)$ & $16.6(2.2)$ \\
\hline $\mathrm{VO}_{2}(\mathrm{l} / \mathrm{min})$ & $0.39(0.08)$ & $0.35(0.02)$ & $0.35(0.03)$ & 0.29 (0.02) \\
\hline $\mathrm{VCO}_{2}(\mathrm{l} / \mathrm{min})$ & $0.28(0.02)$ & $0.30(0.02)$ & $0.30(0.04)$ & $0.25(0.03)$ \\
\hline RER & $0.84(0.02)$ & $0.86(0.03)$ & $0.84(0.05)$ & $0.85(0.06)$ \\
\hline HR (beats/min) & $95.3(4.1)$ & $87.0(2.0)$ & $82.6(6.1)$ & $92.3(3.9)$ \\
\hline $\mathrm{VO}_{2} / \mathrm{HR}$ (ml/beat) & $3.5(0.3)$ & $4.1(0.2)$ & $4.0(0.4)$ & $3.2(0.3) \dagger$ \\
\hline Breathlessness & $0.9(0.4)$ & $1.2(0.4)$ & $0.5(0.2)$ & $0.8(0.3)$ \\
\hline Leg effort & $0.9(0.3)$ & $0.8(0.3)$ & $0.4(0.2)$ & $0.9(0.5)$ \\
\hline \multicolumn{5}{|l|}{ At end of exercise } \\
\hline VE $(I / \mathrm{min})$ & $47.3(2.9)$ & 43.8 (3.7) & $36.3(3.4) \dagger$ & $37.1(3.1)$ \\
\hline $\mathrm{VO}_{2}(\mathrm{l} / \mathrm{min})$ & $0.94(0.06)$ & 0.99 (0.07) & $0.92(0.08)$ & $0.86(0.06)$ \\
\hline $\mathrm{VCO}_{2}(\mathrm{l} / \mathrm{min})$ & $0.90(0.07)$ & $0.96(0.08)$ & $0.82(0.06)$ & $0.82(0.06)$ \\
\hline RER & $0.95(0.03)$ & $0.97(0.04)$ & $0.90(0.03)$ & $0.95(0.01)$ \\
\hline HR (beats/min) & $114.1(6.2)$ & $117.0(6.3)$ & $105.4(3.2)$ & $115.0(3.3)$ \\
\hline $\mathrm{VO}_{2} / \mathrm{HR}$ (ml/beat) & $8.4(0.5)$ & $8.7(0.9)$ & $9.4(0.8)$ & $7.6(0.8)^{* *}$ \\
\hline Breathlessness & $6.4(0.5)$ & $7.0(0.6)$ & $4.0(0.6) \dagger$ & $4.8(0.7) \dagger$ \\
\hline Leg effort & $6.0(0.7)$ & $6.5(0.9)$ & $4.0(0.6)$ & $5.0(0.5)$ \\
\hline \multicolumn{5}{|c|}{$\begin{array}{l}\text { Values are expressed as mean (SE). } \\
* *<<0.01 \text { (BD } v \text { placebo). } \\
t p<0.05 \text { (improvers } v \text { non-improvers). }\end{array}$} \\
\hline
\end{tabular}

then aligning it to the volume of the chest wall measured by OEP. These data show a shift in the average maximum expiratory flow-volume envelope which did not achieve significance for the group as a whole. Improvers reduced their resting EELV after bronchodilator and this change persisted at the end of exercise (fig 7A middle $v$ lower graphs). Non-improvers had a lower EELV during resting breathing relative to their predicted TLC (fig 7B). After exercise post-bronchodilator EELV did not rise and the gas compression artefact (area beyond the MEFV curve) was more evident, in keeping with the increased action of the expiratory muscles in the abdominal compartment fig $7 \mathrm{~B}$ middle $v$ lower graphs).

The values of dyspnoea reported by the non-improvers at the end of exercise were significantly lower $(p<0.05)$ than those reported by the improvers, both after placebo and after bronchodilator treatment (table 4). Within the two groups, bronchodilator treatment did not change the values of either dyspnoea and leg effort at the end of exercise. However, these similar values were obtained after a longer time in improvers than in non-improvers.

\section{DISCUSSION}

Evaluating the effect of bronchodilator treatment on exercise capacity and dyspnoea has proved surprisingly difficult in COPD, with contradictory data being reported with different drug classes in different studies. ${ }^{15}$ More recent studies using long acting inhaled agents have shown improvements in both breathlessness and endurance time, ${ }^{8}$ although not all workers have confirmed the latter effect. ${ }^{9}$ These differences are usually attributed to differences in the exercise protocol used and to random variation in the patient's ability to perform the test. Our data before and after salbutamol suggest an alternative explanation for these findings. While our group as
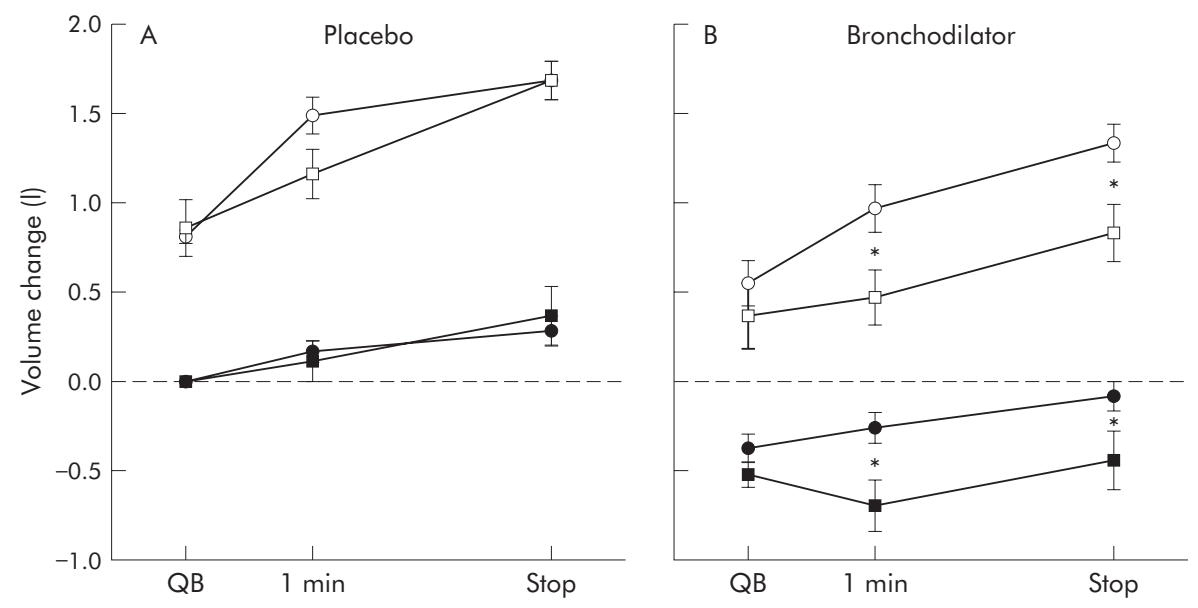

Figure 5 Changes in end expiratory volumes (closed symbols) and end inspiratory volumes (open symbols) after (A) placebo and (B) bronchodilator during quiet breathing (QB), after 1 minute of exercise, and in the 30 seconds before stopping exercise (Stop). The data are divided into those who improved exercise time after bronchodilator (improvers: denoted by circles, $n=12$ ) and those who did not (non-improvers: denoted by squares, $n=6$ ). All values are referred to end expiratory volumes during QB after placebo treatment. Data are expressed as mean (SE). * $\mathrm{p}<0.05$ (improvers $v$ nonimprovers). 

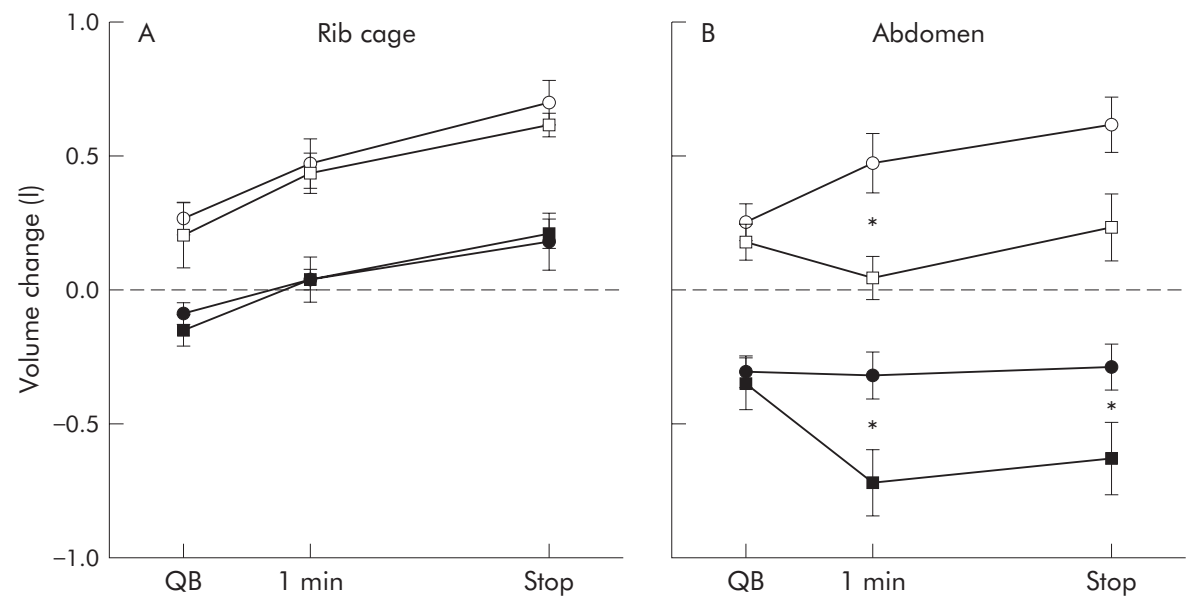

Figure 6 Changes in end expiratory (closed symbols) and end inspiratory (open symbols) rib cage volume (A) and abdomen volume (B) during quiet breathing (QB), after 1 minute of exercise, and in the 30 seconds before stopping exercise (Stop) for improvers (circles, $n=12$ ) and non-improvers (squares, $n=6$ ) after salbutamol. All values are referred to end expiratory volumes during QB after placebo treatment. Data are expressed as mean (SE). ${ }^{*} \mathrm{p}<0.05$ (improvers $v$ non-improvers).

a whole showed the improvement in dynamic hyperinflation reported by others, one third of patients failed to improve their endurance time and they were less severely affected by COPD and showed smaller volume changes at rest. They also adopted a very different pattern of chest wall volume distribution on exercise that we believe helps to explain the unexpected worsening of their exercise performance.
Nebulised salbutamol produced statistically significant increases in $\mathrm{FEV}_{1}, \mathrm{FVC}$, and resting IC with a reduction in FRC and RV. Neither TLC nor FEV $_{1} /$ FVC changed significantly, suggesting that the improvements in expiratory flow were related to changes in operating volume. The constant $\mathrm{FEV}_{1} / \mathrm{FVC}$ ratio suggests that the time constant (resistance $x$ compliance) of the respiratory system did not change after
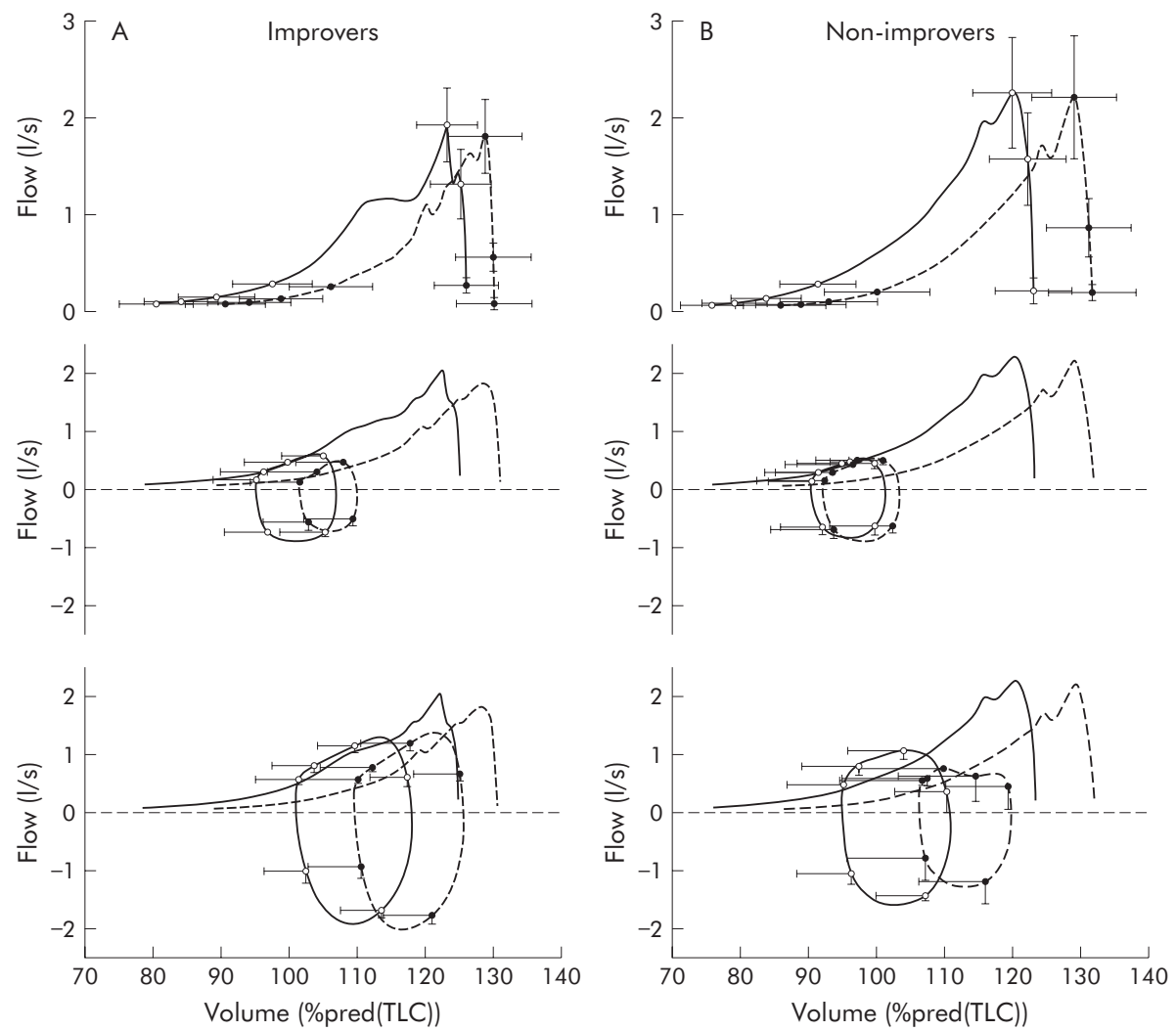

Figure 7 Flow-volume curves obtained during forced expiratory manoeuvre (upper panels), tidal breathing at rest (middle panels) and end exercise (lower panels) in (A) improvers and (B) non-improvers. Maximal expiratory flow-volume (MEFV) curves are repeated in the middle and lower panels for reference. Each curve is the combined average of the individual curves of all patients in these two groups. In each graph the data obtained after treatment with placebo (dashed lines) and salbutamol (solid lines) are reported, while error bars represent standard error of mean flow and volume at $0 \%, 20 \%, 40 \%, 60 \%, 80 \%$ and $100 \%$ of the duration of the manoeuvre or the tidal breath. See text for details. 
the bronchodilator and that the reduction in gas trapping indicated by the increase in FVC was due to the opening of lung units with similar mechanical properties to those functioning before bronchodilation.

The total fall in end expiratory chest wall volume measured by OEP at rest was similar to that identified by body plethysmography, confirming the accuracy of the OEP data. ${ }^{10}$ The change in dynamically regulated volume corresponding to FRC was accompanied by a fall in the volume of the abdominal compartment at rest, while the reduction in RV was equally distributed between rib cage and abdominal compartments. This change in chest wall shape after the bronchodilator suggests that, at rest, the diaphragm was relatively longer and potentially capable of greater force generation as observed previously. ${ }^{9}$ It is also likely that the change in lung volume influenced the length of the abdominal muscles with consequences on their activation in response to loading. ${ }^{16}$ The pooled end expiratory and end inspiratory total chest wall volume data during endurance exercise resemble those seen with other bronchodilator drugs where end expiratory lung volume has been measured indirectly. ${ }^{8}$

Despite the improved lung and chest wall mechanics, we saw no significant difference in exercise duration or end of exercise symptoms in this patient group. We examined a range of characteristics at rest and during exercise that might explain this heterogeneous response to the bronchodilator. Separating patients into improvers and non-improvers highlighted several important differences. Patients who improved were older, had worse airflow obstruction, higher resting lung volumes, and worse exercise performance after placebo than non-improvers. Only $\mathrm{FEV}_{1}$ (both absolute and \% predicted) was significantly lower after the bronchodilator. However, in the improvers there was an increase of about $18 \%$ in FVC after bronchodilator compared with a change of about $8 \%$ in non-improvers. This greater reduction in gas trapping may reflect the greater degree of hyperinflation seen at rest in the improvers.

Most of our patients would not be considered reversible using currently recommended criteria, ${ }^{17}$ despite the statistically significant improvement in expiratory flow in the group as a whole. Reliance on changes in IC would have been better, but an improvement in resting IC of more than $200 \mathrm{ml}$ (day to day reproducibility ${ }^{18}$ was still seen in subjects who subsequently failed to improve their exercise capacity.

Non-improvers had better spirometric results after salbutamol than those whose performance improved. It is unlikely that they stopped exercising because of a limited ventilatory reserve. We believe that differences in the activation of the chest wall muscles after the bronchodilator explain this apparently paradoxical behaviour. The results during the placebo test were similar, irrespective of the subsequent response to bronchodilator. However, patients whose exercise endurance improved after treatment showed a significant fall in chest wall volume after the bronchodilator, but adopted the same pattern of progressive hyperinflation during exercise at this lower operating volume. In contrast, those with worse exercise performance after bronchodilator treatment were now able to reduce their end expiratory chest wall volume after 1 minute of exercise, although this tended to rise as exercise ended. These changes in chest wall volume were due to differences in the volume of the abdominal but not the rib cage compartment. The distribution of volume during exercise after the bronchodilator resembles that seen in some healthy subjects when exercising while breathing through a Starling resistor, ${ }^{19}{ }^{20}$ and is qualitatively similar to the euvolumic pattern reported previously. ${ }^{2}$ Figure 7 indicates that there was dynamic gas compression/blood shift occurring at maximal exercise in the non-improvers after salbutamol. Previous work suggests that excessive abdominal muscle activation can impair venous return, decrease cardiac output, ${ }^{21} 22$ and shift blood from the thorax to the extremities. $^{219} 20$ Oxygen pulse-an indirect measure of cardiac output and a reliable guide to exercise performance in $\mathrm{COPD}^{23}$-fell in the non-improvers, suggesting that this mechanism might be operative in our patients.

Why these breathing patterns should be adopted is not clear. One possibility could be that the reduction in FRC in the less severely affected patients changed either the ability of the diaphragm to generate force and displace volume or the way in which expiratory muscles are acting. There may be variable degrees of abdominal muscle recruitment by reflex mechanisms in COPD patients which explain these differing responses. ${ }^{24}$ Alternatively, the breathing strategy adopted when patients develop expiratory flow limitation during tidal breathing may be a learned response that is influenced by the degree of expiratory flow reserve, as suggested previously. ${ }^{2}$ Future studies should examine the relationship between abdominal muscle use and expiratory flow limitation which can now be studied non-invasively and continuously. ${ }^{25}$

In our study the end of exercise Borg score was not influenced by treatment. However, there was a clear positive effect on the isotime Borg score compared with placebo, and no evidence of benefit in this variable in the nonimprover group. This is not likely to be due to a simple regression to the mean effect as the order of placebo therapy was randomised. Patients adopting a euvolumic breathing pattern spontaneously before bronchodilatation are as breathless when they stop as hyperinflating patients who exercise for longer. ${ }^{2}$ Whether this reflects the greater degree of expiratory muscle activation, as suggested in studies of healthy individuals, ${ }^{26}$ or has some other mechanism is still to be determined.

Our data require some qualification. Although this was a blind crossover trial, the data only apply to one postbronchodilator exercise study and it would be unwise to extrapolate further until the consistency of the response pattern on repeated testing and on different days is established. We used a large dose of salbutamol high on the dose-response curve established using a spirometric outcome, ${ }^{27}$ and the relevance of this to lower doses is less certain. The complexity of the protocol limited the number of patients recruited, and the number of non-improvers selected by our arbitrary response criterion was underpowered to exclude a difference in several of the explanatory variables. However, the large differences in the chest wall volume response to exercise is unlikely to have arisen by chance, given the small variation in these variables after placebo treatment which was itself administered in random order.

In summary, we have confirmed that nebulised $\beta$ agonists reduce end expiratory chest wall volume during endurance exercise in patients with stable COPD. However, the ability to exercise soon after receiving active treatment is influenced by the degree of pre-bronchodilator pulmonary hyperinflation and the way in which the chest wall muscles adapt to the change in lung mechanics produced by the bronchodilator. Patients with less hyperinflation may, paradoxically, do worse after treatment by adopting a physiologically inappropriate breathing strategy. These data help explain why a subjective report of the effectiveness of treatment by patients is more valuable than reliance on spirometric changes. In addition, it shows that a deterioration in exercise performance after active treatment can have a physiological basis rather than simply arising by chance. It also highlights the need to understand how and in what circumstances patients with COPD permit their end expiratory lung volume to rise during exercise. 


\section{Authors' affiliations}

A Aliverti, R L Dellacà, A Lo Mauro, A Pedotti, Dipartimento di Bioingegneria, Politecnico di Milano, Italy

K Rodger, N Stevenson, P M A Calverley, University Department of Medicine, University Hospital Aintree, Liverpool, UK

This work was supported in part by the European Community CARED FP5 project (contract number QLG5-CT-2002-0893).

\section{REFERENCES}

1 Anon. Chronic obstructive pulmonary disease. National clinical guideline on management of chronic obstructive pulmonary disease in adults in primary and secondary care. Thorax 2004:59(Suppl I): 1-232.

2 Aliverti A, Stevenson N, Dellacà RL, et al. Regional chest wall volumes during exercise in chronic obstructive pulmonary disease. Thorax 2004;59:210-6.

3 Jones PW. Health status measurement in chronic obstructive pulmonary disease. Thorax 2001;56:880-7.

4 Sutherland ER, Cherniack RM. Management of chronic obstructive pulmonary disease (review). N Engl J Med, 2004;24, 350:2689-97

5 Hay JG, Stone P, Carter J, et al. Bronchodilator reversibility, exercise performance and breathlessness in stable chronic obstructive pulmonary disease. Eur Respir J 1992:5:659-64.

6 O'Donnell DE, Fluge T, Gerken F, et al. Effects of tiotropium on lung hyperinflation, dyspnoea and exercise tolerance in COPD. Eur Respir 2004;23:832-40.

7 O'Donnell DE, Lam M, Webb KA. Spirometric correlates of improvement in exercise performance after anticholinergic therapy in chronic obstructive pulmonary disease. Am J Respir Crit Care Med 1999; 160:542-9.

8 O'Donnell DE, Voduc N, Fitzpatrick M, et al. Effect of salmeterol on the ventilatory response to exercise in chronic obstructive pulmonary disease. Eur Respir J 2004;24:86-94.

9 Man WD, Mustfa N, Nikoletou D, et al. Effect of salmeterol on respiratory muscle activity during exercise in poorly reversible COPD. Thorax 2004;59:471-6.

10 Duranti $\mathbf{R}$, Filippelli $M$, Bianchi $R$, et al. Inspiratory capacity and decrease in lung hyperinflation with albuterol in COPD. Chest 2002;122:2009-14.

11 British Thoracic Society. BTS guidelines for the management of chronic obstructive pulmonary disease. The COPD Guidelines Group of the Standards of Care Committee of the BTS. Thorax 1997;52(Suppl 5):S1-28.
12 American Thoracic Society. ATS Statement Snowbird Workshop on Standardization of Spirometry. Am Rev Respir Dis 1979:831-8.

13 Cala SJ, Kenyon CM, Ferrigno G, et al. Chest wall and lung volume estimation by optical reflectance motion analysis. J Appl Physiol 1996;81:2680-9.

14 Borg GA. Psychophysical bases of perceived exertion. Med Sci Sports Exerc 1982;14:377-81.

15 Liesker JJ, Wijkstra PJ, Ten Hacken NH, et al. Systematic review of the effects of bronchodilators on exercise capacity in patients with COPD. Chest 2002; 121:597-608

16 Iscoe S. Control of abdominal muscles (review). Prog Neurobiol 1998;56:433-506

17 Pauwels RA, Buist AS, Calverley PMA, et al. Global strategy for the diagnosis, management, and prevention of chronic obstructive pulmonary disease. Am J Respir Crit Care Med 2001;163:1256-76.

18 Hadcroft J, Calverley PM. Alternative methods for assessing bronchodilator reversibility in chronic obstructive pulmonary disease. Thorax 2001:56:713-20.

19 landelli I, Aliverti A, Kayser B, et al. Determinants of exercise performance in normal men with externally imposed expiratory flow-limitation. J Appl Physiol 2002;92:1943-52.

20 Aliverti A, landelli I, Duranti R, et al. Respiratory muscle dynamics and control during exercise with externally imposed expiratory flow-limitation. J Appl Physiol 2002;92:1953-63.

21 Stark-Leyva, Kristy N, Ken C Beck, et al. Johnson. Influence of expiratory loading and hyperinflation on cardiac output during exercise. J Appl Physiol 2004:96:1920-7.

22 Simon $M$, LeBlanc $P$, Jobin J, et al. Limitation of lower limb $\mathrm{VO}_{2}$ during cycling exercise in COPD patients. J Appl Physiol 2001;90:1013-9.

23 Montes de Oca M, Rassulo J, Celli BR. Respiratory muscle and cardiopulmonary function during exercise in very severe COPD. Am J Respir Crit Care Med 1996; 154:1284-9.

24 Polkey MI, Kyroussis D, Hamnegard CH, et al. Diaphragm performance during maximal voluntary ventilation in chronic obstructive pulmonary disease. Am J Respir Crit Care Med 1997;155:642-8.

25 Dellacà RL, Santus $P$, Aliverti $A$, et al. Detection of expiratory flow limitation in COPD using the forced oscillation technique. Eur Respir J 2004;23:232-40.

26 Kayser B, Sliwinski S, Yan S, et al. Respiratory effort sensation during exercise with induced expiratory flow limitation in healthy humans. J Appl Physiol 1997:83:936-47.

27 Vathenen AS, Britton JR, Ebden P, et al. High-dose inhaled albuterol in severe chronic airflow limitation. Am Rev Respir Dis 1988;138:850-5.

\section{bmjupdates+}

bmjupdates+ is a unique and free alerting service, designed to keep you up to date with the medical literature that is truly important to your practice. bmjupdates+ will alert you to important new research and will provide you with the best new evidence concerning important advances in health care, tailored to your medical interests and time demands.

Where does the information come from?

bmjupdates+ applies an expert critical appraisal filter to over 100 top medical journals A panel of over 2000 physicians find the few 'must read' studies for each area of clinical interest

Sign up to receive your tailored email alerts, searching access and more...

www.bmjupdates.com 